\title{
Short communication: Effect of oregano and caraway essential oils on the production and flavor of cow milk
}

\author{
J. Lejonklev, ${ }^{*}$ U. Kidmose, $†$ S. Jensen, $\dagger^{1}$ M. A. Petersen, $\ddagger$ A. L. F. Helwing,§ G. Mortensen, ${ }^{* 2}$ \\ M. R. Weisbjerg, $\S^{3}$ and M. K. Larsen*4 \\ *Department of Food Science, AU Foulum, Aarhus University, Blichers Allé 20, PO Box 50, DK-8830 Tjele, Denmark \\ †Department of Food Science, AU Aarslev, Aarhus University, Kirstinebjergvej 10, PO Box 102, DK-5792 Årslev, Denmark \\ fDepartment of Food Science, University of Copenhagen, Rolighedsvej 30, DK-1958 Frederiksberg C, Denmark \\ §Department of Animal Science, AU Foulum, Aarhus University, Blichers Allé 20, PO Box 50, DK-8830 Tjele, Denmark
}

\section{ABSTRACT}

Many essential oils and their terpene constituents display antimicrobial properties, which may affect rumen metabolism and influence milk production parameters. Many of these compounds also have distinct flavors and aromas that may make their way into the milk, altering its sensory properties. Essential oils from caraway (Carum carvi) seeds and oregano (Origanum vulgare) plants were included in dairy cow diets to study the effects on terpene composition and sensory properties of the produced milk, as well as feed consumption, production levels of milk, and methane emissions. Two levels of essential oils, 0.2 and $1.0 \mathrm{~g}$ of oil $/ \mathrm{kg}$ of dry matter, were added to the feed of lactating cows for 24 d. No effects on feed consumption, milk production, and methane emissions were observed. The amount and composition of volatile terpenes were altered in the produced milk based on the terpene content of the essential oils used, with the total amount of terpenes increasing when essential oils were added to the diet. Sensory properties of the produced milk were altered as well, and milk samples from animals receiving essential oil treatment were perceived as having a fresher aroma and lower stored aroma and flavor. The levels of essential oils used in this study mimic realistic levels of essential oils in herbs from feed, but were too low to affect milk production and methane emissions, and their inclusion in the animal diet did not adversely affect milk flavor.

Key words: caraway, flavor, methane, oregano

\footnotetext{
Received January 18, 2016.

Accepted July 5, 2016.

${ }^{1}$ Current address: Carlsberg A/S, Group R\&D, Gamle Carlsberg vej 4, DK-1799, Copenhagen V, Denmark.

${ }^{2}$ Current address: Arla Foods amba, Sønderh $\varnothing$ j 14, DK-8260, Viby, Denmark.

${ }^{3}$ Corresponding author: martin.weisbjerg@anis.au.dk

${ }^{4}$ Current address: Arla Foods amba, ARINCO, Maelkevejen 2-4, DK-6920, Videbaek, Denmark.
}

\section{Short Communication}

Herbal plants are commonly included in bovine feeding as a result of their presence in pasture (Søegaard et al., 2011), but they can also be actively included in the diet to obtain an effect on milk production parameters, such as milk yield and methane production (Abo El-Nor et al., 2007; Hristov et al., 2013). Rather than using whole herbal matter, essential oils can be derived from plants and seeds by steam distillation. These oils contain large amounts of monoterpenes and sesquiterpenes and have strong flavor and smell notes (Simon, 1990). They can be included in animal feeding, as they contain numerous secondary plant metabolites that have been identified as potentially beneficial feed additives for ruminants to improve milk productivity and animal health (Benchaar et al., 2008; Giannenas et al., 2011) as well as to reduce methane emissions of which domesticated ruminants are a large contributor (Bodas et al., 2012). In addition to milk production parameters, the addition of essential oils to animal feed could potentially affect the milk flavor. The sensory quality of the milk can be affected by feeding essential oils due to either a direct transfer of aroma compounds from the feed to the milk or due to the formation of aroma compounds during digestion of the feed (Carpino et al., 2004). Terpenes are common in many types of animal feed and can readily be transferred into milk, both through the gastrointestinal tract and through the lungs of the animal (Viallon et al., 2000; Prache et al., 2005; Lejonklev et al., 2013). The objective of the present study was to explore how the addition of caraway and oregano essential oils to the feed of Holstein dairy cows, at 2 levels comparable to those that could be obtained by adding herbs to the diet, would affect milk production, milk composition, methane emissions, and the volatile composition and sensory properties of the produced milk.

The essential oils used for the study were obtained commercially from New Directions (Hampshire, UK), and were produced by steam distillation of caraway 
seeds and oregano herbs. Essential oils were added to the feed at $0.2 \mathrm{~g}$ of oil $/ \mathrm{kg}$ of DM for the low level and $1.0 \mathrm{~g}$ of oil $/ \mathrm{kg}$ of DM for the high level. Assuming an essential oil content of $20 \mathrm{~g} / \mathrm{kg}$ of DM, this corresponded to a diet with $50 \%$ of DM from grass forage, where 2 to $10 \%$ consists of herbal matter, which is feasible in Danish grazing systems (Søegaard et al., 2011). Fifteen Danish Holstein cows, with a live weight ranging from 500 to $700 \mathrm{~kg}$ and a BCS between 2.5 and 3.5, were used for the experiment, which lasted $24 \mathrm{~d}$. Cows were blocked according to lactation (first, second, and more than 2) and randomly allocated within block to the 5 different treatments: control, low caraway content, high caraway content, low oregano content, and high oregano content (3 animals for each treatment). Days in milk ranged from 46 to 142 at the start of the experiment. The TMR fed to the cows were identical, except for the added essential oils, and consisted of barley (12.1\%), soybean meal (11.2\%), rapeseed cake (10.1\%), grass-clover silage $(30.2 \%)$, maize silage $(35.0 \%)$, and minerals $(1.4 \%)$. Chemical composition of ration, in percentage of DM, was ash (6.5\%), CP (16.8\%), NDF $(32.3 \%)$, fat (3.5\%), linolenic acid (1.0\%), and linolenic acid $(0.4 \%)$. Fresh feed and essential oil mixtures were prepared once a day. The TMR was mixed as one batch per day and divided into 5 portions, approximately 150 to $200 \mathrm{~kg}$ each. The essential oils were added to the individual portions and mixed further. Separate mixers were used for the oregano and caraway treatments, and the treatments with the low concentration of essential oils were always mixed before the treatments with high concentration.

During d 1, all cows received feed without added essential oils. Feed consumption was recorded daily throughout the experiment. Samples of individual feed items for proximate and fatty acid analysis of the diets were taken once a week and stored at $-20^{\circ} \mathrm{C}$. The feed samples were later pooled to 2 samples; one covering the first $2 \mathrm{wk}$ of the experiment and the other covering the last $2 \mathrm{wk}$ of the experiment. The TMR samples for terpene analysis were obtained in the morning of $\mathrm{d} 2$, 9, 16, and 23, collected in glass containers, and stored at $-20^{\circ} \mathrm{C}$. During d $1,3,10,17$, and 24 , milk production data were recorded, and milk samples, as mixtures of morning and evening milk, were collected in glass containers and stored at $-20^{\circ} \mathrm{C}$ until analysis for milk composition and terpenes. Milk samples for sensory testing were obtained at 2 occasions by mixing evening milk from d 23 with morning milk d 24, and evening milk from d 24 with morning milk d 25. Within $6 \mathrm{~h}$ after morning milking, the mixed milk was pasteurized $\left(72^{\circ} \mathrm{C}, 15 \mathrm{~s}\right)$, poured into glass containers, placed on ice, and kept at $1^{\circ} \mathrm{C}$ until sensory analysis was carried out the following day. Concentrations of fat, protein, and lactose were analyzed using a Milkoscan 4000 (Foss Analytical, Hillerød, Denmark). The fatty acid content was analyzed in feed samples as well as milk samples, as described by Larsen et al. (2012), with the exception of heptane being used as solvent instead of pentane. Feed samples were freeze-dried and ground through a 1-mm mesh before chemical analyses of DM, ash, nitrogen, crude fat, and NDF. The DM concentration of feed samples was determined by drying the samples for $48 \mathrm{~h}$ at $60^{\circ} \mathrm{C}$. Ash was determined by combustion at $525^{\circ} \mathrm{C}$ for $6 \mathrm{~h}$. Nitrogen was determined by the Dumas principle, as described by Hansen (1989), using a Vario MAX CN (Elementar Analysesysteme GmbH, Hanau, Germany). Crude protein was calculated as 6.25 times the measured nitrogen concentration. Crude fat was determined by Soxhlet extraction with petroleum ether (Soxtec 2050, Foss Analytical) after hydrolysis with hydrochloric acid (Stoldt, 1952). Ash-free NDF was measured using a Fibertec M6 System (Foss Analytical) using heat-stable amylase and sodium sulfite, as described by Mertens (2002). The gross energy concentration was calculated according to Volden and Nielsen (2011).

Methane emission was measured for $48 \mathrm{~h}$, once for each cow during the experiment in the period 8 to $17 \mathrm{~d}$ after the start of the experiment, similar to the method described in Hellwing et al. (2012). One control cow was measured twice to maximize the use of measuring equipment. Terpene analysis of milk samples was performed using dynamic headspace sampling according to Lejonklev et al. (2013). Feed samples were analyzed the same way, but by using $5 \mathrm{~g}$ of the final mixture for each type of feed suspended in $20 \mathrm{~mL}$ of Milli-Q water. A trained sensory panel of 8 to 10 assessors, consisting of 7 to 9 females and 1 male, aged 26 to $61 \mathrm{yr}$, evaluated the 5 milk samples quantitatively using sensory profiling. The assessors were tested and trained in accordance to international standards (ISO, 1993). The sensory evaluation was carried out in a sensory evaluation laboratory fulfilling the requirements provided by the ASTM (1986). Prior to each sensory evaluation, the assessors attended a 2 h-training session, where the assessors were introduced to 3 milk samples that differed significantly in several of the selected attributes. The samples consisted of a commercial milk sample and the milk samples from cows fed with high levels of oregano and caraway. As inspiration, the assessors were introduced to reference samples as described by Hedegaard et al. (2006). Based on this, a sensory profile of 15 attributes for milk was developed by the panelists before the evaluation. The milk samples were served in small plastic beakers with lids (Abena A/S, Aabenraa, Denmark) in amounts of approximately $50 \mathrm{~mL}$ at a temperature of 16 to $18^{\circ} \mathrm{C}$. The samples were coded and 
served in random order to avoid bias. The samples were served in 4 replicates each day during 2 consecutive days. PanelCheck v. 1.4.0226 (www.PanelCheck.com) was used for assessor evaluation. After each training session, the assessors received feedback on their performance using PanelCheck to improve and standardize the panel's discriminating power. During training and evaluation, the attributes were evaluated on a $15-\mathrm{cm}$, nonstructured, continuous scale and the ratings were registered directly in a personal computer registration system (Fizz software, 2.30C, Biosystemes, Couternon, France). Energy-corrected milk (3.14 MJ/kg) was calculated according to Sjaunja et al. (1991).

Recoveries of C18:2n-6 and C18:3n-3 were calculated for individual cows as the ratio between the total amount of each FA excreted in milk per day and the total amount of the same FA ingested from feed per day. Peak areas of volatile terpene compounds in milk were $\log$ 10-transformed before analysis to ensure uniform variance. Statistical analysis of data was performed in SAS (SAS Institute Inc., Cary, NC). Data for feed consumption, milk production, milk composition (fat, protein), milk fatty acid composition, fatty acid recovery, and volatile terpene compounds in milk were analyzed with a model in Proc Mixed, including response on d 1 before onset of treatment as covariate, and treatment as fixed effect. The cow was random, and covariance between repeated measures within cow was modeled with an autoregressive model. Methane data were analyzed with a model in Proc Mixed including treatment, lactation number, and repetition as fixed effects, where repetitions were treated as repeated measures with compound symmetry as covariance structure. Effect of the 5 treatments on the different sensory attributes was analyzed using the GLM procedure of SAS version 9.1 for Windows (SAS Institute Inc.). Statistical significance was defined at $P \leq 0.05$. The significant differences between the treatments were assessed by least square distance values.

The DMI, milk yield, milk fat concentration, and ECM yield were not affected by treatment (Table 1).
Feed fatty acid content was identical for all treatments because essential oils did not contribute to fatty acids. The content of linoleic and linolenic acid in milk fat did not differ between treatments (Table 1), nor was the recovery of these fatty acids affected by treatments. These results indicate that the applied amounts of essential oils did not affect the biohydrogenation significantly. Methane emission results are presented in Table 2. Gross energy lost as methane was between 5 and $6 \%$ and corresponds well with data for cows fed a forage-to-concentrate ratio of 65:35 (Brask et al., 2013). Production parameters, such as milk yield, have been affected by addition of whole plants or seeds to feed (Abo El-Nor et al., 2007; Søegaard et al., 2011), although the amount of plants or seeds in these studies corresponds to a similar or lower level of essential oils compared with the present study. This could be due to the different amounts of nutrients, including fatty acids in the feed, introduced by the herbal matter, or by other bioactive compounds present in the whole herbal matter, but not in the steam-distilled essential oil. The addition of an essential oils preparation to feed for dairy ewes can result in an increased milk yield at lower levels than those used in our study (Giannenas et al., 2011). This may be the result of the specific tailored essential oil mixture used, rather than one obtained from herbal matter.

The results from the terpene analysis of feed and milk samples are presented in Tables 3 and 4, respectively. The total peak area is presented as the sum of log 10-transformed values, whereas the relative distribution was calculated on nontransformed values to paint a clearer picture of the results. The results indicate that very small proportions of the essential oil terpenes were transferred into milk. As terpenes are common in most types of animal forage (Prache et al., 2005), it was not unexpected that the control feed contained all of the analyzed terpenes. The addition of essential oils to the feed resulted in higher total amounts of terpenes and a shift in terpene distribution. Caraway feed became dominated by limonene and carvone, whereas

Table 1. Least squares means of DMI, milk yield, ECM yield, milk composition, and recovery ${ }^{1}$ of linoleic and linolenic acid

\begin{tabular}{|c|c|c|c|c|c|c|c|}
\hline Item & Control & $\begin{array}{c}\text { Caraway } \\
\text { low }\end{array}$ & $\begin{array}{c}\text { Caraway } \\
\text { high }\end{array}$ & $\begin{array}{c}\text { Oregano } \\
\text { low }\end{array}$ & $\begin{array}{c}\text { Oregano } \\
\text { high }\end{array}$ & SEM & $P$-value \\
\hline DMI $(\mathrm{kg} / \mathrm{d})$ & 21.5 & 21.2 & 21.7 & 21.4 & 22.2 & 0.52 & 0.83 \\
\hline Milk yield ( $\mathrm{kg} / \mathrm{d})$ & 35.7 & 36.2 & 34.3 & 36.2 & 34.5 & 0.65 & 0.34 \\
\hline $\operatorname{ECM}(\mathrm{kg} / \mathrm{d})$ & 35.9 & 35.0 & 35.9 & 34.7 & 35.4 & 0.83 & 0.79 \\
\hline Milk fat (g/kg) & 43.2 & 40.5 & 42.7 & 39.5 & 40.9 & 1.95 & 0.65 \\
\hline Milk protein $(\mathrm{g} / \mathrm{kg})$ & 31.2 & 32.8 & 32.8 & 31.7 & 31.5 & 0.38 & 0.06 \\
\hline Linoleic acid (g/kg of FA) & 15.0 & 14.9 & 14.9 & 15.7 & 15.6 & 0.6 & 0.76 \\
\hline Linolenic acid ( $\mathrm{g} / \mathrm{kg}$ of $\mathrm{FA}$ ) & 3.7 & 3.7 & 3.8 & 3.9 & 3.9 & 0.1 & 0.75 \\
\hline Linoleic acid recovery (\%) & 12.3 & 11.1 & 10.5 & 10.5 & 10.5 & 0.8 & 0.44 \\
\hline Linolenic acid recovery $(\%)$ & 7.0 & 6.5 & 6.1 & 6.1 & 6.1 & 0.3 & 0.17 \\
\hline
\end{tabular}

${ }^{1}$ Recovery is calculated as the amount of fatty acid excreted in milk relative to the amount ingested from feed. 
Table 2. Least squares means of methane emissions in liter per day, per kilogram of DMI, and as a percentage of gross energy intake (GEI) lost as methane ${ }^{1}$

\begin{tabular}{|c|c|c|c|c|c|c|c|}
\hline Item & Control & $\begin{array}{c}\text { Caraway } \\
\text { low }\end{array}$ & $\begin{array}{c}\text { Caraway } \\
\text { high }\end{array}$ & $\begin{array}{c}\text { Oregano } \\
\text { low }\end{array}$ & $\begin{array}{c}\text { Oregano } \\
\text { high }\end{array}$ & $\mathrm{SEM}^{2}$ & $P$-value \\
\hline No. of animals & 4 & 3 & 3 & 3 & 3 & & \\
\hline $\mathrm{CH}_{4}(\%$ of $\mathrm{GEI})$ & 5.8 & 5.4 & 5.5 & 5.7 & 5.4 & 0.4 & 0.76 \\
\hline
\end{tabular}

${ }^{1}$ Only DMI recorded during chamber stay was used for the calculations. $\mathrm{N}=$ number of observations.

${ }^{2} \mathrm{SEM}$ differs for the control, as one cow was measured twice.

oregano feed displayed great increases of $\rho$-cymene, carvacrol, and sesquiterpenes. These increases of specific compounds were consistent with those terpenes being abundant in the oils used, which has previously been analyzed by Lejonklev et al. (2013). However, the proportions were different, most apparent in the high level of sesquiterpenes in oregano feed compared with the low levels found in pure essential oils. The likely explanations for these discrepancies were differences in analytical methods for essential oils and feed samples, differences in interactions between feed components and individual terpenes, as well as loss of volatile monoterpenes during feed preparation compared with the less volatile sesquiterpenes (Coppa et al., 2011).

Milk samples from essential oil feeding had greater total contents of terpenes. It is likely that the volatile terpenes were absorbed and transferred into milk through both respiratory and gastrointestinal pathways when they were added to the feed (Lejonklev et al., 2013). Control milk was characterized by the same terpenes as those found in the control feed, though in different proportions, with carvone, limonene, and $\rho$-cymene being the most abundant together with $\alpha$-pinene and 3 -carene included in the other monoterpene category at 20 and $12 \%$, respectively. This shift in proportions between feed and milk was present for the different treatments as well. Several potential explanations for this exist, including different transfer rates for different terpenes, metabolic activity turning one compound into another, as well as the analytical method being influenced by the different matrices of the 2 types of samples. Several different terpenes in treatment milk samples displayed a significant increase compared with the control $(P<$ 0.001 ), despite quite variable values between different animals. Differences in milk composition between individual animals may be a factor in explaining the differences in milk terpene content. Treatment milk samples became dominated by the terpene most abundant in their respective feed, limonene for caraway milk and $\rho$-cymene for oregano milk. Neither carvone, present in caraway feed, or carvacrol, present in oregano feed, increased significantly in any milk samples, when compared with the control. As these 2 compounds were the second most abundant terpenes in their respective feed, these results suggest that carvone and carvacrol were metabolized in some way.

A suggested alteration is presented in Figure 1, which would also assist in explaining the increasing amounts of limonene and $\rho$-cymene in treatment milk samples due to reduction of the alcohol functional group of carvacrol and the ketone functional group of carvone. The same dominant compounds are reported after respiratory or intestinal transfer (Lejonklev et al., 2013), which demonstrates that the reduction is possible while

Table 3. Terpene content in feed samples as LSM of log 10-transformed sum of peak areas, and percent of non-log-transformed total peak area

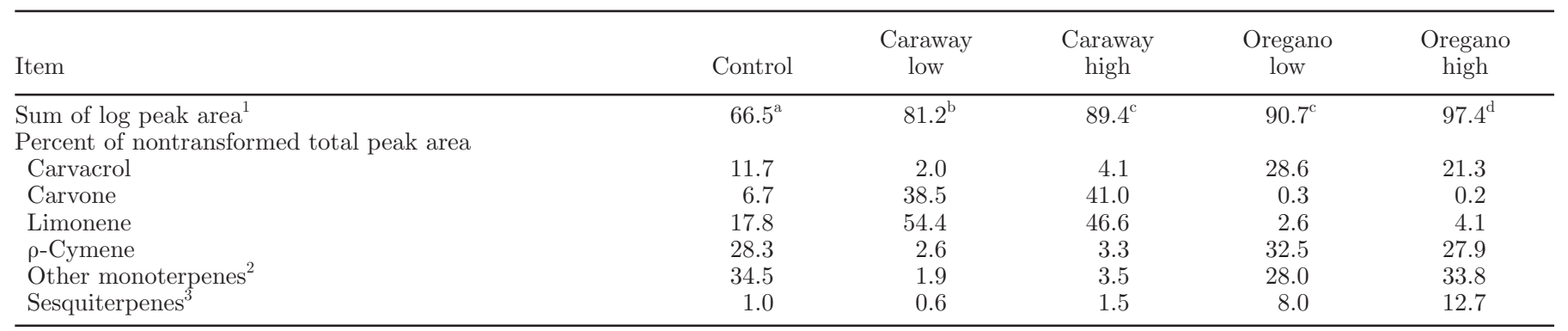

\footnotetext{
${ }^{\mathrm{a}-\mathrm{d}}$ Different letters within row indicate significant difference $(P<0.05)$.

${ }^{1}$ For the sum of log peak area, SEM was 0.8 and statistical difference was defined at $P<0.001$.

${ }^{2}$ Includes $\alpha$-pinene, $\beta$-pinene, 3 -carene, myrcene, $\alpha$-terpinene, $\gamma$-terpinene, terpinolene, and $\alpha$-terpineol.

${ }^{3}$ Includes $\beta$-caryophyllene and $\alpha$-humulene.
} 
Table 4. Terpene content in milk samples as LSM of log 10-transformed sum of peak areas and percent of non-log-transformed total peak area

\begin{tabular}{|c|c|c|c|c|c|}
\hline Item & Control & $\begin{array}{c}\text { Caraway } \\
\text { low }\end{array}$ & $\begin{array}{c}\text { Caraway } \\
\text { high }\end{array}$ & $\begin{array}{c}\text { Oregano } \\
\text { low }\end{array}$ & $\begin{array}{c}\text { Oregano } \\
\text { high }\end{array}$ \\
\hline Sum of log peak area ${ }^{1}$ & $38.7^{\mathrm{a}}$ & $44.1^{\mathrm{ab}}$ & $58.0^{\mathrm{bc}}$ & $56.8^{\mathrm{bc}}$ & $62.9^{\mathrm{c}}$ \\
\hline \multicolumn{6}{|c|}{ Percent of nontransformed total peak area } \\
\hline Carvone & 25.4 & 13.4 & 11.6 & 2.7 & 0.7 \\
\hline Limonene & 14.7 & 69.1 & 81.0 & 4.9 & 2.5 \\
\hline$\rho$-Cymene & 15.8 & 6.1 & 2.5 & 59.4 & 62.5 \\
\hline
\end{tabular}

\footnotetext{
${ }^{\mathrm{a}-\mathrm{c}}$ Different letters within row indicate significant difference $(P<0.05)$.

${ }^{1}$ For the sum of log peak area, SEM was 2.4 and statistical difference was defined at $P<0.001$.

${ }^{2}$ Includes $\alpha$-pinene, $\beta$-pinene, 3 -carene, myrcene, $\alpha$-terpinene, $\gamma$-terpinene, terpinolene, and $\alpha$-terpineol.

${ }^{3}$ Includes $\beta$-caryophyllene and $\alpha$-humulene.
}

compounds are present in the blood stream or in the udder. Mammal metabolism of terpenes generally alters the compounds into more polar ones, for example through hydroxylation, followed by excretion in urine (Sapra et al., 2008). However, the metabolic pathway proposed in Figure 1 results in less polar compounds. In addition, rumen bacteria are able to alter the chemical structure of terpene compounds by saturation of double bonds, oxygen removal, and opening of ring structures (Malecky et al., 2009), though absorption of volatile terpenes through the lungs and intestines would bypass such alterations. As both carvone and carvacrol were present in control feed, their static presence in milk samples, including the control, could possibly be explained by some form of protection from metabolic alterations present for terpenes originating from the plants of the feed, but not for those terpenes added in the form of essential oils. Such protection would have allowed these terpenes to pass unaltered into the milk, resulting in a consistent amount for both control and treatment. The increase in milk terpene composition was observed after $2 \mathrm{~d}$ of essential oil exposure, which is consistent with published data that transfer of mono- and sesquiterpenes into milk does not require prolonged exposure (Viallon et al., 2000; Poulopoulou et al., 2012). However, both of these studies observed
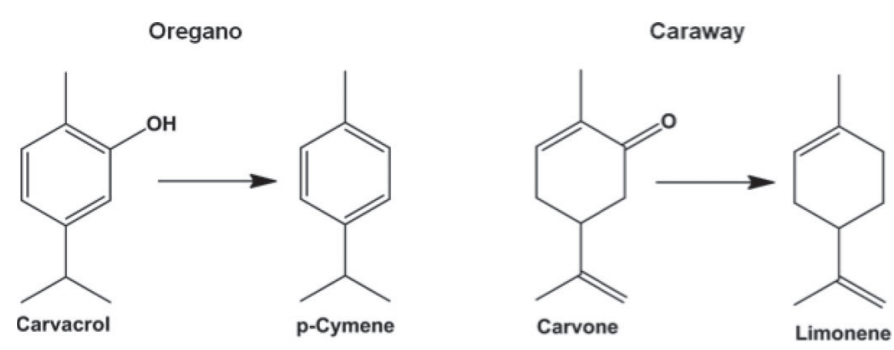

Figure 1. Proposed metabolic alterations to carvacrol and carvone. a decrease of milk terpene content over time after the initial increase, which was not present in this study, as we found no significant differences between sampling days for the sum or the individual terpene content in milk samples.

Six sensory attributes were affected by treatments (Table 5). Essential oil treatments generally resulted in milk with fresh aroma and flavor and a lower corn aroma, UHT milk aroma, as well as stored aroma and flavor, except that milk from the high oregano treatment did not differ from control for corn aroma, stored aroma, and fresh aroma. The sensory characteristics relating to herbs that were used in our study, caraway flavor and green herb flavor, received very low scores (between 0.5 and 3.0) for all milk samples with no significant differences. These results are consistent with the observation that neither carvone nor carvacrol increased in treatment milk samples, as both of these terpenes are known to have an herbaceous aroma (Fahlbusch et al., 2005). Instead the observed similarities in sensory characteristics for treatment milk samples may have been the result of the similar aromas of limonene, the most abundant terpene in caraway milk, and $\rho$-cymene, the most abundant in oregano milk, which are lemon-like for limonene and weak citrus for $\rho$-cymene (Fahlbusch et al., 2005).

As the addition of essential oils did not affect the flavor adversely and has shown potential in reducing methane emissions in vitro, additional research could be justified to determine the effects of long-term exposure and higher doses and to further investigate ways to achieve reduction of methane emissions by both essential oils and whole plants and seeds.

\section{ACKNOWLEDGMENTS}

The authors acknowledge the financial support from The Danish Ministry of Food, Agriculture and Fish- 
Table 5. Mean scores for sensory attributes that displayed significant differences

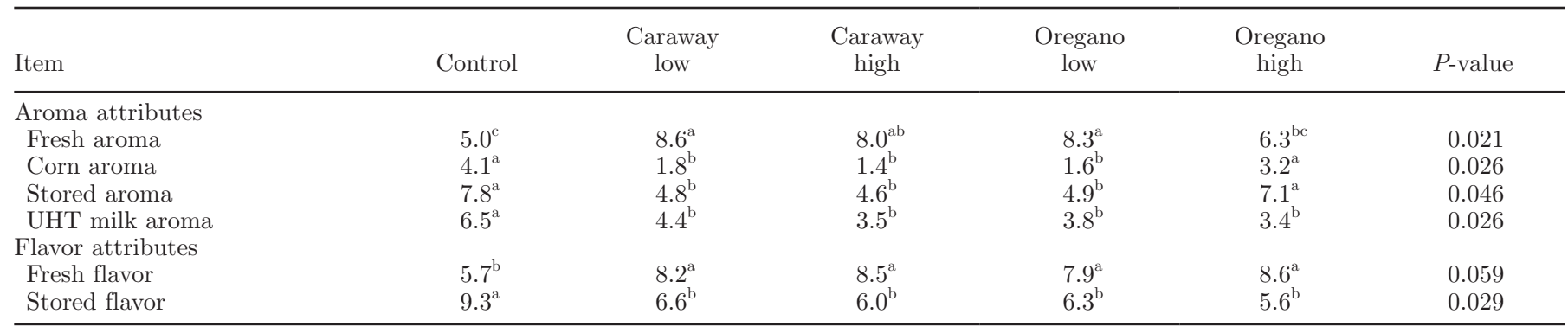

${ }^{a-c}$ Different letters within row indicate significant difference.

eries (Copenhagen, Denmark), Arla Foods (Aarhus, Denmark), and DLF Trifolium (Roskilde, Denmark).

\section{REFERENCES}

Abo El-Nor, S. A. H., H. M. Khattab, H. A. Al-Alamy, F. A. Salem, and M. M. Abdou. 2007. Effect of some medicinal plants seeds in the rations on the productive performance of lactating buffaloes. Int. J. Dairy. Sci. 4:348-355. http://dx.doi.org/10.3923/ ijds.2007.348.355.

ASTM. 1986. Committee E-18. Physical requirement guidelines for sensory evaluation laboratories. Pages 1-54 in ASTM Special Technical Publication 913, Vol. 913. J. Eggertj, K. Zook, ed. American Society for Testing and Materials, Philadelphia, PA.

Benchaar, C., S. Calsamiglia, A. V. Chaves, G. R. Fraser, D. Colombatto, T. A. McAllister, and K. A. Beauchemin. 2008. A review of plant-derived essential oils in ruminant nutrition and production. Anim. Feed Sci. Technol. 145:209-228.

Bodas, R., N. Prieto, R. García-González, S. Andrés, F. J. Giráldez, and S. López. 2012. Manipulation of rumen fermentation and methane production with plant secondary metabolites. Anim. Feed Sci. Technol. 176:78-93.

Brask, M., P. Lund, A. L. F. Hellwing, M. Poulsen, and M. R. Weisbjerg. 2013. Enteric methane production, digestibility and rumen fermentation in dairy cows fed different forages with and without rapeseed fat supplementation. Anim. Feed Sci. Technol. 184:67-79.

Carpino, S., J. Horne, C. Melilli, G. Licitra, D. M. Barbano, and P. J. Van Soest. 2004. Contribution of native pasture to the sensory properties of Ragusano cheese. J. Dairy Sci. 87:308-315.

Coppa, M., B. Martin, P. Pradel, B. Leotta, A. Priolo, and V. Vasta. 2011. Effect of a hay-based diet or different upland grazing systems on milk volatile compounds. J. Agric. Food Chem. 59:4947-4954.

Fahlbusch, K.-G., F.-J. Hammerschmidt, J. Panten, P. Wilhelm, and D. Schatkowski. 2005. Flavors and fragrances. Pages 73-198 in Ullmann's Encyclopedia of Industrial Chemistry, Electronic Release. 7th ed. Wiley-VCH, Weinheim, Germany.

Giannenas, I., J. Skoufos, C. Giannakopoulos, M. Wiemann, O. Gortzi, S. Lalas, and I. Kyriazakis. 2011. Effects of essential oils on milk production, milk composition, and rumen microbiota in Chios dairy ewes. J. Dairy Sci. 94:5569-5577.

Hansen, B. 1989. Determination of nitrogen as elementary N, as an alternative to Kjeldahl. Acta Agric. Scand. 39:113-118.

Hedegaard, R. V., D. Kristensen, J. H. Nielsen, M. B. Frøst, H. Østdal, J. E. Hermansen, M. Kröger-Ohlsen, and L. H. Skibsted. 2006. Comparison of descriptive sensory and chemical analysis for oxidative changes in milk. J. Dairy Sci. 89:495-504.

Hellwing, A. L., P. Lund, M. R. Weisbjerg, M. Brask, and T. Hvelplund. 2012. Technical note: Test of a low-cost and animal-friendly system for measuring methane emissions from dairy cows. J. Dairy Sci. 95:6077-6085.

Hristov, A. N., C. Lee, T. Cassidy, K. Heyler, J. A. Tekippe, G. A. Varga, B. Corl, and R. C. Brandt. 2013. Effect of Origanum vulgare
L. leaves on rumen fermentation, production, and milk fatty acid composition in lactating dairy cows. J. Dairy Sci. 96:1189-1202.

ISO. 1993. ISO 8586. Sensory analysis - General guidance for the selection, training and monitoring of assessors-Part 1: Selecting assessors. International Organization for Standardization, Geneva, Switzerland.

Larsen, M. K., L. Hymøller, D. B. Brask-Pedersen, and M. R. Weisbjerg. 2012. Milk fatty acid composition and production performance of Danish Holstein and Danish Jersey cows fed different amounts of linseed and rapeseed. J. Dairy Sci. 95:3569-3578.

Lejonklev, J., M. M. Løkke, M. K. Larsen, G. Mortensen, M. A. Petersen, and M. R. Weisbjerg. 2013. Transfer of terpenes from essential oils into cow's milk. J. Dairy Sci. 96:4235-4241.

Malecky, M., V. Fedele, and L. P. Broudiscou. 2009. In vitro degradation by mixed rumen bacteria of 17 mono- and sesquiterpenes typical of winter and spring diets of goats on Basilitica rangelands (southern Italy). J. Sci. Food Agric. 89:531-536.

Mertens, D. R. 2002. Gravimetric determination of amylase-treated neutral detergent fiber in feeds with refluxing in beakers or crucibles: Collaborative study. J. AOAC Int. 85:1217-1240.

Poulopoulou, I., E. Zoidis, E. T. Massouras, and I. Hadjigeorgiou. 2012. Terpenes transfer to milk and cheese after oral administration to sheep fed indoors. J. Anim. Physiol. Anim. Nutr. (Berl.) 96:172-181.

Prache, S., A. Cornu, J. L. Berdague, and A. Priolo. 2005. Traceability of animal feeding diet in the meat and milk of small ruminants. Small Rumin. Res. 59:157-168.

Sapra, B., S. Jain, and A. K. Tiwary. 2008. Percutaneous permeation enhancement by terpenes: Mechanistic view. AAPS J. 10:120-132.

Simon, J. E. 1990. Essential oils and culinary herbs. Pages 472-483 in Advances in New Crops, 1st ed. J. Janick and J. E. Simon, ed. Timber Press, Portland, OR.

Sjaunja, L. O., L. Baevre, L. Junkkarinen, J. Pedersen, and J. Setala. 1991. A Nordic proposal for an energy corrected milk (ECM) formula. Performance Recording of Animals. State of the Art 1990. EAAP Publication 50:156-157.

Søegaard, K., J. Eriksen, and M. Askegaard. 2011. Herbs in high producing organic grassland-Effect of management. Pages 190-193 in Proceedings of the Third ISOFAR Scientific Conference: Organic Is Life - Knowledge for Tomorrow. Organic Crop Production. Vol. 1. International Society of Organic Agriculture Research (ISOFAR), c/o Institute of Organic Agriculture, University of Bonn, Bonn, Germany.

Stoldt, W. 1952. Vorslag zur Vereinheitlichung der Fettbestimmung in Lebensmitteln. Eur. J. Lipid Sci. Technol. 54:206-207.

Viallon, C., B. Martin, I. Verdier-Metz, P. Pradel, J. P. Garel, J. B. Coulon, and J. L. Berdague. 2000. Transfer of monoterpenes and sesquiterpenes from forages into milk fat. Lait 80:635-641.

Volden, H., and N. I. Nielsen. 2011. Energy and metabolizable protein supply. Pages 81-84 in NorFor-The Nordic Feed Evaluation System, 1st ed, Vol. 130. H. Volden, ed. Wageningen Academic Publishers, Wageningen, the Netherlands. 